\title{
O DISCURSO FASCISTA E SUAS IMPLICAÇÕES PARA A EDUCAÇÃO DOS POVOS DO CAMPO E INDÍGENAS
}

\author{
The fascist discourse and its implications for the education of rural and \\ indigenous populations
}

Luiz Otávio Costa MARQUES

Universidade Federal dos Vales do Jequitinhonha e Mucuri

luiz.marques@ufvjm.edu.br https://orcid.org/0000-0001-7139-3137

Paulo Afranio SANT'ANNA

Universidade Federal dos Vales do Jequitinhonha e Mucuri pauloasantanna@ufvjm.edu.br https://orcid.org/0000-0002-8284-1481

Neste artigo, trazemos reflexões sobre enunciados de cunho fascista que têm emergido no Brasil nos últimos anos e seus impactos nas políticas públicas educacionais voltadas para a diversidade cultural dos povos do campo e indígenas no país. Julgamos que a análise de discursos de tal natureza, evidenciando suas origens e possíveis consequências nas práticas sociais de nossa população, mais especificamente, de populações subalternizadas, como os indígenas e os sujeitos do campo, possa contribuir para a construção de contradiscursos e de estratégias de resistência e combate a essas narrativas de viés discriminatório. A escolha de enunciados do atual presidente da república como material de análise se deve ao fato de que o discurso da autoridade máxima do país reflete a ideologia em evidência no atual governo.

O termo "fascista" utilizado neste texto deve ser lido "sob rasura", pois, quando nos referimos a "discurso fascista" não nos referimos ao discurso fascista clássico, que emergiu na Itália e na Alemanha nas décadas de 1920 e 1930 no contexto da Segunda Guerra Mundial (KONDER, 2009) ${ }^{2}$. Referimo-nos, mais precisamente, às narrativas de

\footnotetext{
${ }^{1}$ Colocar um conceito "sob rasura", marcando-o e rasurando-o, é uma estratégia desenvolvida pelo filósofo pós-estruturalista Jacques Derrida (1981), utilizada para desconstruir conceitos-chave, imprimindo um outro sentido a eles.

${ }^{2}$ De acordo com Konder (2009, p. 53), “o fascismo é uma tendência que surge na fase imperialista do capitalismo, que procura se fortalecer nas condições de implantação do capitalismo monopolista de Estado,
} 
natureza fascista ou melhor, neofascistas, que surgiram nos últimos anos no Brasil, e que dialogam estreitamente com o fascismo clássico, principalmente no que tange à questão do autoritarismo, do conservadorismo de cunho religioso, da manipulação ideológica visando à instauração de uma perspectiva hegemônica, da ideia de uma raça superior e da manutenção de privilégios de determinadas classes sociais. Não é nosso objetivo, portanto, discutir com aprofundamento todos esses aspectos, mas sim focalizar uma das características do fascismo, o mito de nação, visto que ele contribui para a reflexão sobre nosso objeto de análise.

O mito de nação consiste em uma ideia de país como uma suposta unidade homogênea, idealizada e livre de conflitos. Tal concepção foi esboçada primeiramente por Mussolini no início da primeira grande guerra mundial (KONDER, 2009), quando ele percebeu a necessidade de se criar um valor supostamente supremo, com base na fé e na paixão pela pátria, e que fosse capaz de mobilizar e unificar a sociedade italiana. Nas palavras de Konder (2009, p. 35),

Era imprescindível um princípio sagrado, posto acima de qualquer discussão, imune a qualquer dúvida, capaz de funcionar como bússola quando o barco tivesse de manobrar em meio à tempestade, um valor supremo que nunca se degradasse e pudesse alimentar incessantemente a chama da fé no coração dos combatentes.

Desse modo, no fascismo clássico, o mito da nação, da pátria, da cultura nacional, além de servir de ponto de referência em períodos de instabilidade política, objetiva escamotear e/ou silenciar as diferenças, os conflitos internos, a luta de classes, o racismo, assim como forjar uma suposta homogeneidade nacional. Faz parte dessa construção simbólica a identificação de inimigos internos e externos, os quais precisam ser combatidos por um governo forte e pleno de poderes. Nos momentos de crise econômica e política, apelar para o nacionalismo fascista é uma estratégia para levar a população como um todo a se sentir pertencente a uma identidade nacional, uma construção a qual Anderson (1983 apud HALL, 1998) chamou de comunidade imaginada.

exprimindo-se através de uma política favorável à crescente concentração do capital; é um movimento político de conteúdo social conservador, que se disfarça sob uma máscara "modernizadora", guiado pela ideologia de um pragmatismo radical, servindo-se de mitos irracionalistas e conciliando-os com procedimentos racionalistas-formais de tipo manipulatório. O fascismo é um movimento chauvinista, antiliberal, antidemocrático, antissocialista, antioperário". 
No Brasil, o mito de nação emergiu de diversas formas em momentos históricos distintos, como no Estado Novo da era Vargas entre 1937 e 1945 e no período da ditadura militar entre 1964 e 1985. Mais recentemente, ele tem se tornado cada vez mais evidente, como, por exemplo, nas manifestações políticas a favor do atual governo. Nestas, a manipulação simbólica de elementos tradicionais da identidade nacional, como a bandeira do país e as camisetas da seleção brasileira, assim como a demonização da esquerda e dos grupos minoritários, visam evocar um sentimento nacionalista associado a uma figura salvadora, o presidente, que, segundo esse discurso, irá reconduzir o país na direção da integridade moral e do pleno desenvolvimento. Da mesma forma, a disseminação do nacionalismo fascista pode ser observada nas redes sociais por meio da profusão de informações difusas e/ou de fontes questionáveis, as quais favorecem a manipulação de fatos, como é o caso das fake news, e a construção de narrativas que propagam o ódio e a polarização da sociedade entre direita e esquerda, e legitimam as políticas discriminatórias do atual governo.

Com base nessa breve contextualização do conceito de fascismo utilizado neste artigo, discutiremos os traços de nacionalismo fascista no discurso do presidente da república ao evocar o mito de nação, ou seja, a ideia de uma suposta homogeneidade do povo brasileiro fundamentada no ideário da elite conservadora, cristã, branca, patriarcal e urbana, que nega a diversidade cultural e racial no país. Para esta discussão selecionamos dois excertos para serem analisados. O primeiro foi proferido em abril de 2017, durante uma palestra no Clube em Hebraica, em Laranjeiras, Zona Sul do Rio de Janeiro. O presidente, então deputado federal, ao mencionar uma visita realizada a uma comunidade quilombola, relatou o seguinte: "Fui num quilombo. O afrodescendente mais leve lá pesava sete arrobas. Não fazem nada! Eu acho que nem para procriador ele serve mais. Mais de R\$ 1 bilhão por ano é gasto com eles" ${ }^{3}$. O segundo foi proferido em janeiro de 2020 por meio de um vídeo publicado pelo presidente em redes sociais. No vídeo, ele afirma: "O índio mudou, tá evol... Cada vez mais, o índio é um ser humano igual a nós. Então, vamos fazer com que o índio se integre à sociedade e seja realmente dono da sua

\footnotetext{
${ }^{3}$ CONGRESSO EM FOCO. Bolsonaro: “Quilombola não serve nem para procriar”, 05 abr. 2017. Disponível em: <https://congressoemfoco.uol.com.br/especial/noticias/bolsonaro-quilombola-nao-servenem-para-procriar/>. Acesso em: 09 jul. 2020.
} 
terra indígena, isso é o que a gente quer aqui" ${ }^{4}$.

Nesses excertos, o presidente se refere às populações do campo, mais especificamente, aos povos quilombolas e aos indígenas de forma visivelmente discriminatória. À primeira vista, o que nos chama atenção é que o presidente afere qualidades não-humanas tanto aos quilombolas quanto aos indígenas. No primeiro excerto, para descrever um afrodescendente que ele conheceu em um quilombo, ele usa o termo "arroba", unidade de medida utilizada na pesagem de animais como bovinos e suínos. A seguir, o presidente afirma que o afrodescendente "não serve nem para procriador", termo também utilizado na agropecuária para distinguir os animais destinados à reprodução no rebanho. A "lógica do rebanho" tem suas raízes no período imperial brasileiro em que "escravos procriadores" eram bastante valorizados pelos seus senhores. Para ter um valor comercial alto, o negro tinha que poder procriar. Se não procriava, valia menos. Ou seja, verifica-se que esse excerto é atravessado pelo discurso colonial racista que atribui ao negro uma condição inferior, sub-humana, ligada à natureza e à irracionalidade, discurso esse que naturaliza a subalternização do negro em nossa sociedade.

Já no segundo excerto, o presidente se refere ao indígena como alguém que está cada vez mais se parecendo com "os seres humanos igual a nós". Infere-se que esse "nós" se refira ao cidadão brasileiro, branco, capitalista e cristão que vive no contexto urbano. Ou seja, o indígena em questão estaria, em sua visão, em um suposto processo de "evolução" ao sair de um patamar considerado por ele "inferior" ao do homem branco "civilizado", tentando se aproximar do modo de vida típico desse homem branco. Sua fala, portanto, nos leva a inferir que, dentro de seu modo interpretativo, este indígena deveria ser "resgatado" desse lugar por ele considerado como "inferior", deixando de lado suas crenças e seu modo de vida. Tornar-se "civilizado", dentro dessa visão, implica também tornar-se proprietário da terra, ou seja, aderir ao ideário do capitalismo. O presidente parece desconhecer completamente o sentido que a terra tem para o indígena como lugar de produção de vida e não como mercadoria.

Portanto, o mito de nação de viés fascista se evidencia quando o presidente nega a

\footnotetext{
${ }^{4}$ G1. 'Cada vez mais, o índio é um ser humano igual a nós', diz Bolsonaro em transmissão nas redes sociais, 24 jan. 2020. Disponível em: <https://g1.globo.com/politica/noticia/2020/01/24/cada-vez-mais-o-indio-eum-ser-humano-igual-a-nos-diz-bolsonaro-em-transmissao-nas-redes-sociais.ghtml>. Acesso em: 20 jul. 2020 .
} 
condição humana dos povos quilombolas e indígenas, não os posicionando como cidadãos brasileiros. Infere-se que, para se fazer parte do que ele considera como "povo brasileiro", é preciso se enquadrar no estilo de vida determinado pelas elites que estão no poder e compartilhar seus valores e crenças. Nessa visão reducionista e excludente do que é ser um cidadão brasileiro, observa-se a desqualificação de grande parte da população brasileira, o que discursivamente pode servir como justificativa para o alijamento desses sujeitos de seus direitos básicos, sua dignidade e liberdade. Assim, posicionar os povos quilombolas e indígenas como cidadãos brasileiros, sujeitos de direito, implicaria na desconstrução da visão essencializada e tradicional da identidade nacional brasileira, que os exclui e que desconsidera a heterogeneidade constitutiva do país.

No contexto global marcado pela expansão de governos com visões fascistas, a educação e a comunicação são campos fortemente tensionados e disputados, uma vez que ambos detêm as tecnologias de produção de pensamento crítico. A manipulação de conhecimento e informações visando à construção de uma narrativa homogeneizadora sobre a nação é essencial para a ascensão e manutenção de projetos totalitários. Portanto, tanto a educação como a comunicação são setores estratégicos que costumam ser vigiados e disciplinados pelo aparato ideológico do governo. Desse modo, projetos dissonantes são geralmente extintos e/ou inviabilizados.

No Brasil, podemos considerar como um dos sintomas desse processo a extinção da Secretaria de Educação Continuada, Alfabetização, Diversidade e Inclusão (SECADI/MEC) por meio do Decreto $\mathrm{n}^{\circ} 9.465$ de 2 de janeiro de 2019, um dos primeiros atos do atual governo. Instituída em 2012, tinha como objetivo assegurar o direito à educação com qualidade e equidade por meio do desenvolvimento de políticas públicas educacionais promotoras de inclusão social, orientadas pela valorização das diferenças e da diversidade sociocultural, pelo respeito aos direitos humanos e pela sustentabilidade socioambiental. Em diálogo com os movimentos sociais, a SECADI formulou ações que se estenderam a diversos campos: Educação de Jovens e Adultos, Educação Especial na perspectiva inclusiva, Educação Ambiental e em Direitos Humanos, Educação do Campo, Indígena e Quilombola e Educação para as Relações Étnico-Raciais.

Os programas de Educação do Campo e Educação Indígena são políticas afirmativas que se fundamentam na diversidade étnico-cultural dessas populações. Esses 
programas têm por objetivo garantir uma educação que reconheça e promova a existência dos diversos modos de vida e saberes que compõem o universo cultural dos povos do campo e indígenas, dentro de uma visão dialética dos processos culturais, que não vê qualquer cultura como superior ou inferior a outras, e sim como diferente e igualmente digna de respeito.

A educação do campo e indígena rompem com o paradigma de educação urbanocêntrica, que prevaleceu até o final da década de 1990. Até esse período, às populações indígenas e campesinas eram impostos projetos educativos dissociados da sua realidade sociocultural, nos quais o modo de vida urbano e capitalista era exaltado em detrimento de outras possibilidades de produção de vida. O objetivo desses projetos era produzir o que eles chamavam de "resgate civilizatório", tomando como referência a cultura e valores das classes dominantes, e procurando impor esses valores às demais culturas.

Com a promulgação da Constituição Federal em 1988 e da Lei de Diretrizes e Bases da Educação em 1996, criaram-se as condições para o protagonismo de diversos atores e movimentos sociais na formulação de projetos educacionais voltados para populações específicas, especialmente aquelas cujos direitos foram historicamente negados (MARQUES, 2019). Nesse contexto, surgiu o Movimento de Educação do Campo, que se articula em torno da construção de um novo paradigma de educação para as populações que vivem em áreas rurais. Esse movimento defende um projeto de educação "do" e "no" campo e não "para" o campo, ou seja, um projeto que emane das demandas sociais e culturais dessas populações, respeitando seus saberes e epistemologias, dando visibilidade às suas identidades, promovendo o acesso às políticas públicas e aos direitos constitucionais.

Tal movimento leva em conta que, ao longo do processo de constituição da nação brasileira, as populações indígenas e camponesas foram invisibilizadas e seus saberes e modos de vida foram sistematicamente deslegitimados e desvalorizados. O racismo estrutural, que atravessa todas as esferas da sociedade, reverbera fortemente no discurso de cunho fascista do atual governo, que tenta, mais uma vez, inviabilizar a afirmação da diversidade étnico-racial no país, silenciando as vozes de uma grande parte da população. Ao tratar os quilombolas e indígenas como sub-humanos, como pessoas "inferiores" e 
destituídas de saber, o presidente busca legitimar o desmonte de políticas públicas afirmativas, como o programa de Educação do Campo, que visam compensar o descaso histórico com essas populações. Os setores conservadores que disputam o campo da educação - as igrejas evangélicas, o núcleo ideológico de inspiração olavista e os grandes empresários nacionais e internacionais - indicam a natureza do projeto educacional que se pretende implementar no Brasil. Infelizmente, o cenário que se delineia é sombrio, sobretudo para a educação do campo e indígena.

Este artigo teve como proposta evidenciar esse cunho fascista no discurso do atual presidente, e lembrar de onde vem esse discurso, ou seja, de uma visão do outro como inferior, de alguém que precisa ser "resgatado" no sentido de deixar seus valores e adotar os valores do outro para procurar ser aceito dentro da cultura dominante vigente no país. Esperamos que esta nossa reflexão possa despertar olhares mais críticos para esse discurso político e, quem sabe, trazer mais questionamentos e rupturas a esse modo desrespeitoso de lidar com as populações do campo e indígenas, que ameaça seus poucos direitos, conquistados com muita luta ao longo da história do país.

\section{REFERÊNCIAS}

DERRIDA, J. Positions. Chicago: University of Chicago Press, 1981.

HALL, S. A identidade cultural na pós-modernidade. Trad. Tomaz Tadeu da Silva, Guaraciara Lopes Louro. 2a ed. Rio de Janeiro: DP\&A, 1998.

KONDER, L. Introdução ao Fascismo. $2^{\mathrm{a}}$ ed. São Paulo: Editora Expressão Popular, 2009.

MARQUES, L. O. C. Ensino de Língua Estrangeira, Educação do Campo e Letramentos Críticos: tecendo diálogos. 2019, 333 f. Tese (Doutorado em Letras) - Faculdade de Filosofia, Letras e Ciências Humanas, Universidade de São Paulo (USP), São Paulo, 2019. 